\title{
MAPEAMENTO CONCEITUAL COMO ESTRATÉGIA PARA ROMPER FRONTEIRAS DISCIPLINARES: A ISOMERIA NOS SISTEMAS BIOLÓGICOS*
}

\section{Concept mapping as a tool to break disciplinary boundaries: isomerism in biological systems}

\author{
Paulo Rogério Miranda Correia ${ }^{1}$ \\ John W. A. Donner Jr. ${ }^{2}$ \\ Maria Elena Infante-Malachias ${ }^{3}$
}

\begin{abstract}
Resumo: O mapeamento conceitual foi utilizado como uma ferramenta para verificar as mudanças conceituais de estudantes de Ensino Médio após a realização de atividades didáticas desenvolvidas durante as aulas de Química. O objetivo pedagógico a ser atingido foi romper as fronteiras que segregam o conhecimento científico em disciplinas isoladas. Os estudantes foram intencionalmente provocados a relacionar conceitos de Química e de Biologia, a fim de compreender melhor e explicar as conseqüências biológicas da isomeria. Os mapas conceituais elaborados pelos estudantes, antes e após as atividades propostas, evidenciaram o aparecimento de relações entre conceitos químicos e biológicos, que foram avaliadas qualitativamente. Este trabalho mostra que os mapas conceituais podem ser utilizados como ferramentas para auxiliar o professor na realização de práticas didáticas interdisciplinares na escola, bem como para acompanhar o progresso dos estudantes em direção à interdisciplinaridade.

Palavras-chave: Mapeamento conceitual. Interdisciplinaridade. Isomeria. Bioquímica.

Abstract: Concept mapping was used as a tool for checking the conceptual changes caused by didactic activities implemented during chemistry classes in high school. Its pedagogical aim was to break down the boundaries, which segregate scientific knowledge into isolated disciplines. The students were intentionally provoked to merge concepts from chemistry and biology, in order to better understand and explain the biological consequences of isomerism. The concept maps produced by the students before and after the activities confirmed the appearance of relationships among chemical and biological concepts, which were qualitatively evaluated. This work shows that concept maps can be used to follow the students' progress towards interdisciplinarity, and to help the teacher to devise future classroom activities to reinforce and to expand interdisciplinary relationships.
\end{abstract}

Keywords: Concept mapping. Interdisciplinarity. Isomerism. Biochemistry.

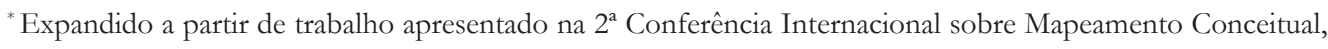
realizada em San Jose, Costa Rica, entre 5 e 8 de setembro de 2006. Menção honrosa do CNPq no $4^{\circ}$ Prêmio Destaque do Ano na Iniciação Científica (2006), na área de Ciências Humanas e Sociais, Letras e Artes.

${ }^{1}$ Licenciado e bacharelado em Química. Pós-doutor em Ciências Exatas e da Terra. Docente, Escola de Artes, Ciências e Humanidades, Universidade de São Paulo (EACH/USP). São Paulo, SP. <prmc@usp.br>

${ }^{2}$ Aluno do curso de Licenciatura em Ciências da Natureza, EACH/USP.

${ }^{3}$ Bióloga. Pós-doutorado em Ensino de Genética. Docente, EACH/USP. <marilen@usp.br>

${ }^{1}$ Avenida Arlindo Bettio, 1000

São Paulo, SP

03.828-000 


\section{Introdução}

O desenvolvimento pleno de uma sociedade justa e igualitária depende da formação de cidadãos críticos e conscientes das suas responsabilidades enquanto partícipes do processo de melhoria e transformação da realidade. Nesse contexto, a educação formal oferecida nas escolas deveria estimular o desenvolvimento do pensamento crítico dos indivíduos (FREIRE, 1996), conferindo à instituição escolar um papel decisivo para alterar o panorama social que predomina no Brasil. O ingresso no sistema educacional, além de proporcionar a possibilidade de inserção na sociedade, permite que o indivíduo desenvolva atitudes que despertem sua preocupação em melhorar a realidade que o cerca em termos econômicos, sociais e ambientais (MORIN, 2002). Desta forma, os objetivos a serem atingidos pelo ensino formal devem transcender os aspectos apenas informativos, que priorizam a mera transmissão do conhecimento relevante acumulado pela humanidade (BRASIL, 1999, 1998). No caso específico do ensino de ciências, deve-se também valorizar o desenvolvimento de competências e habilidades que permitam aos estudantes compreender e utilizar o conhecimento científico como elemento de interpretação de fenômenos cotidianos e de intervenção na realidade (UNESCO, 2005; MENEZES, 2000).

A percepção da ciência como uma prática social relevante e necessária para a resolução ou encaminhamento de muitos problemas da humanidade nunca esteve tão acentuada. A evolução tecnológica do homem acelerou-se enormemente nas últimas décadas, e as conseqüências práticas da ciência tornaram-se cada vez mais evidentes, promovendo mudanças que afetaram drasticamente a forma de viver da população mundial (HOBSBAWN, 2001). Apesar desse papel de destaque, o ensino formal de ciências é pouco estimulante para os estudantes, que não conseguem perceber os aspectos encantadores da constante busca pelo conhecimento. As ciências da natureza são percebidas como um amontoado desconexo de leis e informações com pouco sentido prático (DE MEIS, 2002). Além disso, a escola transmite uma visão distorcida da ciência, que aparece fragmentada, pronta e acabada para os estudantes (KRASILCHIK, 1998). Por outro lado, o entendimento dos processos que ocorrem na natureza exige uma leitura integrada dos conhecimentos especializados das diversas áreas da ciência, tais como: biologia, física, geologia e química (MORAN, 2002).

Essa incongruência leva a uma reflexão mais profunda a respeito do papel da escola e dos níveis básicos da educação. O paradigma disciplinar, como maneira de organizar os conteúdos escolares, há muito vem sendo questionado, e o planejamento das atividades didáticas deve levar em consideração as novas demandas formativas impostas pela sociedade do conhecimento (UNESCO, 2005). A leitura da realidade, repleta de fenômenos complexos que se relacionam entre si, exige um indivíduo que consiga articular, crítica e criativamente, os seus diversos conhecimentos, entre eles os conhecimentos disciplinares, e assim enriquecer e tornar crítico o seu pensamento. Somente desta maneira, a discussão de temas complexos tais como as questões ambientais, os problemas relacionados à saúde e os avanços da tecnologia - será efetivamente viabilizada nas escolas e poderá ter conseqüências reais na sociedade e para a vida dos indivíduos (MORIN, 2002).

A necessidade de se adotar uma abordagem interdisciplinar nos Ensinos Fundamental e Médio é uma das indicações dos documentos oficiais (BRASIL, 1999, 1998), e pode ser considerada como uma das maneiras de superar a fragmentação do conhecimento (MO- 
Mapeamento conceitual como estratégia...

RAN, 2002; KLEIN, 1996). As práticas interdisciplinares evitam que os alunos construam uma visão reducionista das ciências naturais, bem como permitem utilizar assuntos mais interessantes para contextualizar as aulas, favorecendo a integração de conteúdos e expondo os alunos à complexidade do processo de geração do conhecimento. A combinação dessas vantagens pode tornar mais significativa a aprendizagem dos conceitos científicos, despertando o interesse dos alunos para as ciências naturais.

A construção de significados com base no enfoque interdisciplinar amplia a significação de conceitos científicos e reduz a distorção gerada no contexto disciplinar tradicional, no qual a "ciência escolar" apresenta pouca relação com a "ciência dos cientistas", responsável pelos recentes avanços tecnológicos. Uma mudança do panorama encontrado na maioria das salas de aula é indispensável para valorizar a ciência, apresentando-a como algo instigante e desafiador. A disseminação de ações interdisciplinares nas aulas de ciências ainda não é percebida e, quando ocorre, é difícil avaliar seu impacto. Nesse contexto, os mapas conceituais (MCs) podem auxiliar na avaliação desse processo de construção de significados interdisciplinares.

O MC é uma estratégia de meta-aprendizagem baseada na teoria de ensino-aprendizagem proposta por Ausubel (NOVAK, 1990; WANDERSEE, 1990; MOREIRA, MASINI, 1982). Sob a perspectiva ausubeliana, a aprendizagem somente é significativa quando o aluno consegue relacionar significativamente a nova informação a ser aprendida com a sua rede cognitiva. Uma metáfora para esse processo pode ser construída imaginando-se um processo de ancoragem: a rede cognitiva preexistente do aluno oferece ancoradouros ("subsunçores") para interagir com novo conhecimento de forma estável, devido ao processo de significação. Como conseqüência, há modificações na estrutura cognitiva do aluno e sua reestruturação ocorre por meio da construção idiossincrática de significados. Quanto mais intenso for esse processo de ancoragem, mais significativa será a aprendizagem.

Os MCs representam esquematicamente um conjunto de conceitos que se relacionam dois a dois por meio de proposições. Apesar de fundamentados nas idéias de Ausubel, os MCs foram propostos e desenvolvidos por Joseph Novak, e são mais do que diagramas de fluxo: eles explicitam relações significativas entre os conceitos, que podem ser organizados de forma hierárquica (CAÑAS, NOVAK, 2006; NOVAK, 1998). Uma das principais conclusões da Psicologia Cognitiva (ARAUJO E OLIVEIRA, CHADWICK, 2004) indica que os indivíduos tendem naturalmente a estruturar as informações que possuem sobre o mundo, sendo que os MCs permitiriam aumentar e melhorar essa estruturação por meio dos processos de diferenciação progressiva e de reconciliação integrativa que subjazem à aprendizagem significativa.

A utilização dos MCs pode atender diferentes necessidades do meio escolar, tais como: analisar o currículo, estruturar o conteúdo de uma disciplina, organizar os conceitos de uma aula e avaliar a aprendizagem (MOREIRA, BUCHWEITZ, 1993). Nesse último caso, os MCs ajudam a romper o paradigma da prova como instrumento quase exclusivo para essa finalidade. Além disso, a avaliação por meio de MCs não ocorre com a intenção de testar conhecimentos e atribuir nota aos alunos para classificá-los, mas sim com o objetivo de obter informações sobre o tipo de estrutura que o aluno estabelece para um dado conjunto de conceitos. Os MCs elaborados pelos alunos auxiliam na verificação das alterações nas suas redes cognitivas, por meio da comparação das ligações entre os conceitos antes e depois dos momentos de aprendizagem. Outra vantagem associada ao uso dos MCs consiste na possibilidade de se identifica- 
rem os conceitos prévios dos estudantes, que são o fator individual mais relevante para promover a aprendizagem significativa (AUSUBEL, NOVAK, HANESIAN, 1978).

Vários trabalhos da literatura reportam à utilização de MCs no âmbito do ensino de ciências (TSAI, 2000; ROTH, 1994; ROTH, ROYCHOUDHURY, 1994, HORTON, 1993). Apesar da diversidade de aplicações, ainda há espaço para explorar os MCs como ferramentas para avaliar o processo de significação de conceitos interdisciplinares. Nesse caso, os MCs podem mostrar se os alunos estabelecem relações entre saberes de disciplinas diferentes, bem como a maneira pela qual se dá a significação entre os conceitos envolvidos. Surge a possibilidade de monitorar a construção de um discurso que extrapola as fronteiras tradicionais das disciplinas, quando as atividades de sala de aula são especialmente elaboradas para essa finalidade.

Neste trabalho, apresentamos o uso de MCs para monitorar o desenvolvimento da construção de significados interdisciplinares no campo da bioquímica. A isomeria de compostos orgânicos foi contextualizada com base nas suas repercussões nos organismos vivos.

\section{Procedimentos}

A utilização de MCs durante as aulas de Química orgânica ocorreu no $2^{\circ}$ semestre de 2005, com a participação de 32 alunos voluntários da $2^{\mathrm{a}}$ série do Ensino Médio de uma escola particular localizada na região metropolitana de São Paulo. As ações relacionadas com a produção dos MCs foram desenvolvidas como atividade extraclasse à tarde, preservando o horário matutino destinado às aulas regulares de Química. Os encontros vespertinos tinham 100 minutos de duração e o planejamento das atividades considerou a seqüência de conteúdos abordados nas aulas regulares, estabelecida pelo material apostilado utilizado pela professora. A Tabela 1 apresenta a programação prevista pelo material didático adotado na escola, as ações desenvolvidas no período extraclasse e as tarefas a serem cumpridas pelos alunos após os encontros. Algumas das atividades propostas envolveram a elaboração de MCs digitais utilizando o CmapTools, programa de acesso livre que foi desenvolvido pelo Institute for Human and Machine Cognition (IHMC). Nesses casos, a entrega das tarefas ocorreu por correio eletrônico, estendendo a interação com os alunos além dos momentos presenciais na escola.

As atividades extraclasse ocorreram em cinco momentos diferentes ao longo do semestre. O primeiro encontro serviu para apresentar os MCs como uma ferramenta para organizar conceitos, podendo ser utilizada para estudar qualquer assunto. As etapas principais que devem ser observadas no processo de elaboração de MCs foram apresentadas aos alunos na forma de um guia, baseado nas informações disponíveis na literatura (NOVAK, 1984). A prática inicial proposta consistiu na preparação de um MC manuscrito relacionando conceitos sobre química orgânica.

O segundo encontro consistiu na apresentação do programa CMapTools, por meio de uma exposição sobre os procedimentos para instalar o programa e os comandos básicos disponíveis. Posteriormente, foi proposta uma atividade que permitiu aos alunos explorarem os recursos dessa ferramenta: o MC manuscrito, que foi preparado no encontro anterior, deveria ser convertido numa versão digital, elaborada com o auxilio do programa CMapTools. A entrega do arquivo contendo o MC digital foi feita por correio eletrônico, e o prazo máximo para o cumprimento dessa tarefa foi de uma semana. 
Mapeamento conceitual como estratégia...

Tabela 1. Atividades didáticas desenvolvidas na escola, explorando o enfoque disciplinar da professora durante as aulas regulares de Química orgânica e as discussões bioquímicas durante as aulas extras.

\begin{tabular}{|c|c|c|c|}
\hline \multirow[t]{2}{*}{ Semana } & \multicolumn{2}{|r|}{ Tópico } & \multirow{2}{*}{$\begin{array}{l}\text { Tarefa relacionada com a } \\
\text { elaboração de } \mathrm{MCs}^{\mathrm{a}}\end{array}$} \\
\hline & Aulas regulares & Aulas extras & \\
\hline 1 & Isomeria geométrica & Instruções para elaborar MC & $\begin{array}{l}\text { MC manuscrito sobre química } \\
\text { orgânica }\end{array}$ \\
\hline 2 & Isomeria óptica 1 & $\begin{array}{l}\text { Apresentação do programa } \\
\text { CMapTools }\end{array}$ & $\begin{array}{l}M C \text { digital }^{b} \text { a partir do } M C \\
\text { manuscrito sobre química orgânica }\end{array}$ \\
\hline 3 & Isomeria óptica 2 & Discussão sobre o retinal & MC digital ${ }^{\mathrm{b}, \mathrm{c}}$ sobre isomeria \\
\hline 4 & $\begin{array}{l}\text { Reações na química } \\
\text { orgânica } 1\end{array}$ & Discussão sobre a talidomida & - \\
\hline 5 & $\begin{array}{l}\text { Reações na química } \\
\text { orgânica } 2\end{array}$ & $\begin{array}{l}\text { A repercussão da isomeria } \\
\text { nos sistemas vivos }\end{array}$ & $\begin{array}{l}\text { MC digital }{ }^{b, c} \text { relacionando isomeria e } \\
\text { biologia }\end{array}$ \\
\hline
\end{tabular}

${ }^{\mathrm{a} O}$ prazo de entrega das tarefas foi sempre igual a uma semana. ${ }^{\mathrm{b}} \mathrm{O}$ programa CMapTools foi utilizado para elaborar esses MCs. 'A elaboração desses MCs ocorreu em grupos de três ou quatro alunos.

O terceiro e o quarto encontros foram dedicados à introdução intencional de conceitos ligados à bioquímica, que permitiam estabelecer uma relação interdisciplinar com o conteúdo que os alunos haviam estudado nas aulas regulares de química. A isomeria espacial foi o tema selecionado, e sua implicação nos sistemas vivos foi abordada com base na discussão do 11-cis-retinal e da talidomida (ATKINS, 2000). Após o terceiro encontro, os alunos elaboraram um MC digital sobre isomeria, que consistia num subconjunto do MC sobre química orgânica, preparado previamente.

O quinto encontro destinou-se à construção de um MC para verificar a integração entre os conceitos relacionados com a química orgânica, provenientes das aulas regulares, e os conceitos relacionados com a biologia, oriundos das aulas extras. A elaboração do MC começou na sala de aula com a leitura de dois textos pequenos, que resumiam as informações mais importantes sobre o 11-cis-retinal e a talidomida. Esses textos, retirados de um livro didático de química (FELTRE, 2001), são reproduzidos a seguir. A tarefa final proposta aos alunos solicitava o envio do arquivo eletrônico contendo o MC preparado com o auxílio do programa CMapTools dentro do prazo de uma semana. A comparação entre os MC digitais elaborados no terceiro e no quinto encontro permitiu avaliar se houve o estabelecimento de relações interdisciplinares entre os conceitos químicos e biológicos.

"Visão envolve isomeria geométrica"

$\mathrm{Na}$ retina - camada que fica na parte posterior do olho - existem células fotorreceptoras (isto é, receptoras da luz) que contêm uma substância chamada cis-retinal. A incidência de luz provoca a sua transformação em trans-retinal, reação que gera um impulso elétrico que é enviado ao cérebro. Lá os impulsos são interpretados, compondo as imagens que vemos. O olho dispõe de mecanismos capazes de reconverter o trans-retinal em cis-retinal, estando, dessa maneira, pronto para receber mais luz. Em cada segundo, esses eventos se repetem 
milhões de vezes em nossos olhos. O retinal é produzido pelo organismo a partir da vitamina A. A ausência dessa vitamina na dieta alimentar provoca uma doença conhecida como "cegueira noturna", caracterizada pela incapacidade de enxergar em ambientes pouco iluminados. Na cenoura existe uma substância denominada $\beta$-caroteno que, quando ingerida, é convertida em vitamina A. Assim, comer cenouras evita certos tipos de distúrbios visuais. Isto, é claro, não assegura que quem as coma em quantidade vá possuir uma visão acima do normal (como acreditam algumas pessoas), pois a presença de retinal garante, apenas, o funcionamento de parte do aparelho visual.

\section{"Talidomida"}

No início da década de 1960, surgiram informes na Europa, particularmente na Alemanha, de que crianças estavam nascendo deformadas. Seus braços não cresciam, tinham menos ou nenhum dedo, além de outros defeitos. Posteriormente, graças a uma cuidadosa investigação, se pôde determinar que as malformações se deviam a uma substância que as mães haviam ingerido como tranqüilizante para dormir: a talidomida. Ela era encontrada, também, em xaropes contra tosse e era prescrita para reduzir a náusea, tão comum na gravidez. Supõe-se que a talidomida atue sobre o embrião entre o $28^{\circ}$ e o $42^{\circ}$ dia de seu desenvolvimento, quando os braços estão se formando. Esse composto tem um átomo de carbono quiral, havendo, assim, dois enanciômeros ( + e -). O medicamento empregado consistia na mistura racêmica. Depois de sua retirada do mercado, se descobriu que o enanciômero (-) tem propriedades teratogênicas (isto é, produz alterações durante a gravidez), enquanto o $(+)$ é que induz ao sono. Com a talidomida, de uma forma dramática e desafortunada, se fez evidente que a geometria ao redor de um único átomo de carbono pode dar lugar a um medicamento ou a uma substância perigosa.

\section{Resultados e discussão}

A utilização de MCs na sala de aula é uma tarefa motivadora e pouco explorada com os alunos que participaram das atividades aqui descritas. As aulas oferecidas regularmente são expositivas, e o material apostilado, que substitui os livros didáticos, dificulta a integração dos conteúdos das disciplinas e determina a seqüência dos assuntos. Verifica-se uma grande valorização do exame vestibular, que pode ser constatada pela realização periódica de provas que simulam as condições daquele exame. Dentro desse contexto, os papéis tradicionais a serem desempenhados pelos professores e alunos estão bem definidos: o corpo docente deve transmitir os conhecimentos específicos de sua disciplina por meio de aulas expositivas; aos alunos cabe comparecer às aulas e receber as informações. 
Mapeamento conceitual como estratégia...

Ensinar os estudantes a elaborarem os seus próprios MCs é uma poderosa estratégia metacognitiva, fazendo com que os alunos pensem sobre o que aprenderam e sobre como aprenderam. A elaboração dos MCs pode ser manuscrita ou digital, caso o programa CMapTools esteja disponível. Apesar da necessidade de menos recursos para se preparar um MC à mão, as versões digitais dos MCs oferecem uma vantagem atraente: a re-elaboração dos MCs e a organização hierárquica dos conceitos são tarefas realizadas com facilidade pelos alunos. Os MCs manuscritos também podem ser revisados, mas a inclusão de novos conceitos ou o alinhamento deles em níveis hierárquicos são tarefas mais laboriosas. Em algumas situações, os alunos preferem refazer completamente um MC manuscrito, ao invés de refazer somente as partes a serem alteradas. Além disso, os MCs digitais dinamizam a relação estabelecida entre os alunos e o professor, visto que os arquivos podem ser enviados por correio eletrônico. Isso amplia os momentos de estudo para além do horário regular de aulas e impele os alunos a participarem, pois as atividades ocorrem na internet, ambiente muito conhecido para a maioria dos estudantes que participaram desta proposta.

Os MCs sobre Química orgânica elaborados pelos alunos constituíram a primeira atividade deles com o programa CMapTools. O grande desafio dessa etapa, para os alunos, foi interpretar os conceitos de Química orgânica e organizá-los no formato de um MC, explicitando as relações conceituais por meio de proposições. O MC elaborado por um grupo de 3 alunos é apresentado na Figura 1. Ele evidencia as dificuldades que os alunos enfrentaram para organizar os conceitos no formato de um MC, que ficou difícil de compreender devido aos seguintes aspectos: 1) a grande quantidade de conceitos utilizados, 2) a disposição pouco ordenada dos conceitos selecionados, e 3) os termos de ligação utilizados que, por serem muito simples (por exemplo: é, pode ser, que são), não expressam relações sofisticadas entre os conceitos. De qualquer maneira, o conjunto de MCs obtidos nessa atividade permitiu verificar que os conceitos relacionados com a Química orgânica foram organizados de acordo com a seqüência didática das aulas regulares de Química, resumindo os conceitos mais relevantes. Há uma clara valorização de aspectos classificatórios, geralmente abordados nas aulas iniciais de Química orgânica: tipos de carbono, tipos de cadeias carbônicas e funções orgânicas. Não há nenhuma contextualização desses conceitos expressa nos MCs, refletindo que a Química orgânica é introduzida de forma árida para os alunos, que não conseguem relacionar esse conhecimento escolar com suas experiências prévias.

A Figura 2 apresenta um dos MCs produzidos pelos alunos, organizados em grupos de 4 ou 5 componentes. O excessivo número de conceitos presentes nos MCs sobre Química orgânica (Figura 1) direcionou a atividade seguinte e restringiu a temática a somente um tópico da Química orgânica: nessa ocasião, o MC deveria tratar exclusivamente da isomeria. O aumento do foco no assunto a ser mapeado levou à diminuição de conceitos relacionados, facilitando a organização deles por meio de proposições que expressam relações mais sofisticadas. A compreensão dos MCs sobre isomeria foi mais rápida devido à objetividade dos alunos em abordar o tema. Um aspecto comum a todos os MCs preparados nessa atividade foi a presença exclusiva de conceitos químicos, reforçando o caráter disciplinar das aulas regulares freqüentadas pelos alunos. 


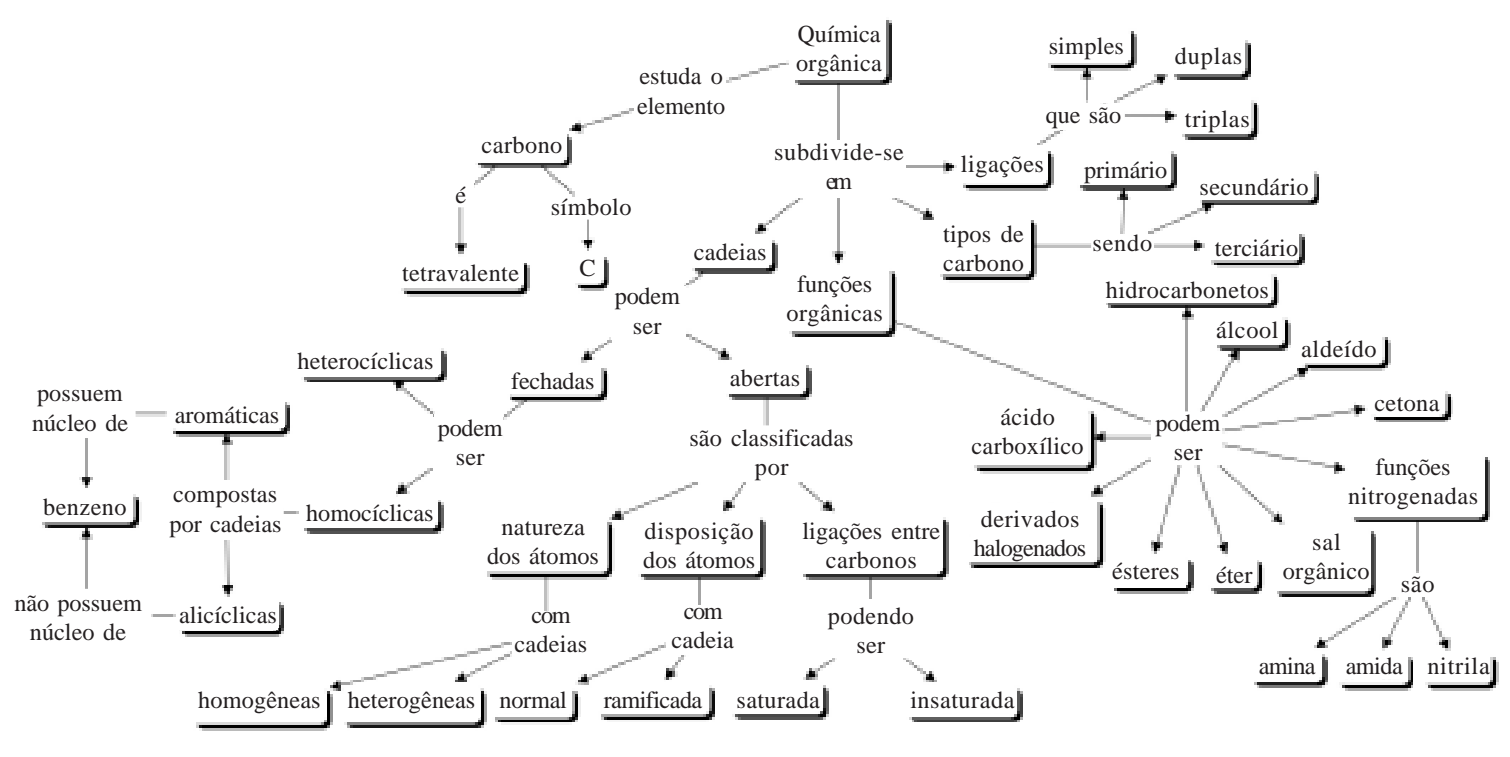

Figura 1. MC sobre química orgânica produzido pelos alunos, como tarefa do encontro 2.

Após as discussões extraclasse sobre as repercussões biológicas da isomeria (Tabela 1), foi proposta uma última atividade: a elaboração de um novo MC sobre isomeria. A leitura de textos sobre o 11-cis-retinal e a talidomida foi feita antes de os alunos trabalharem em grupos de 4 a 5 componentes, a fim de resgatar os conceitos apresentados no terceiro e no quarto encontros. O resultado final obtido nessa atividade (Figura 3) foi muito diferente em comparação aos MCs sobre isomeria previamente preparados (Figura 2). A coexistência de conceitos provenientes da Química (aulas regulares) e da Biologia (aulas extraclasse) nos MCs sugere que algumas relações interdisciplinares foram estabelecidas pelos alunos.

A comparação minuciosa dos MCs sobre isomeria, produzidos antes e depois da discussão biológica sobre isomeria, evidencia que a relação entre os conceitos químicos (Figura 2) é extremamente estável e reproduzida no MC que contém relações interdisciplinares (Figura 3). Isso mostra que os conceitos discutidos durante as aulas regulares fazem sentido para os alunos dentro de uma rede cognitiva específica, que relaciona os conceitos escolares proveniente das aulas de Química para compreender a isomeria. Por esse motivo, nenhum tipo de contextualização apareceu espontaneamente antes das atividades didáticas que visavam o estabelecimento de relações interdisciplinares. 
Mapeamento conceitual como estratégia...

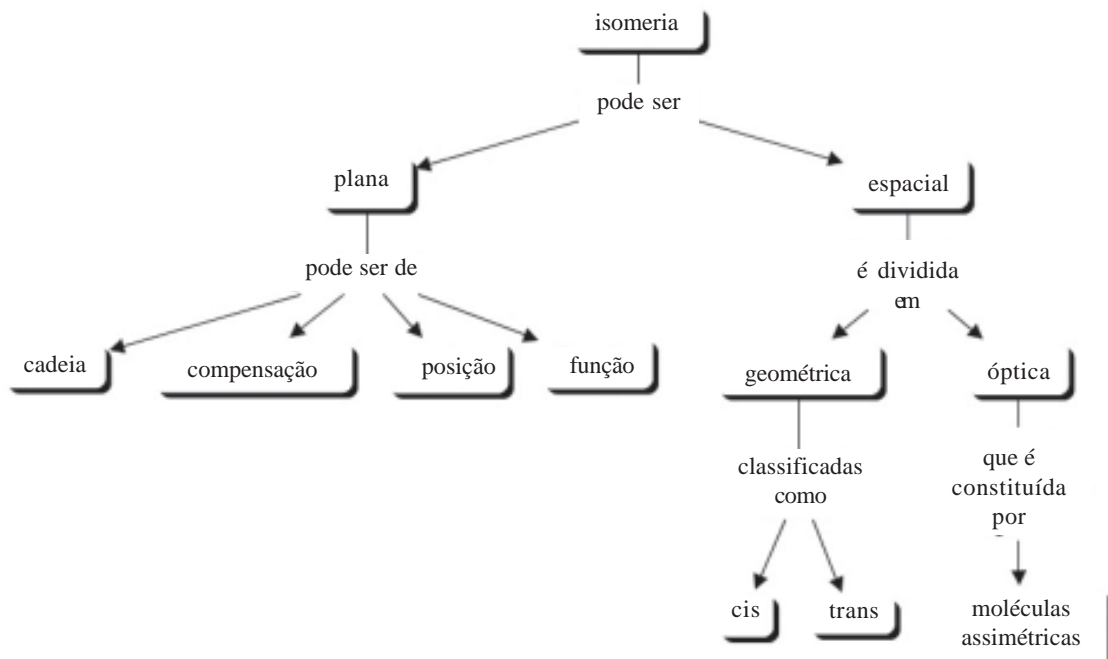

Figura 2. MC sobre isomeria produzido pelos alunos, como tarefa do encontro 3 , antes da discussão sobre as repercussões da isomeria em organismos vivos.

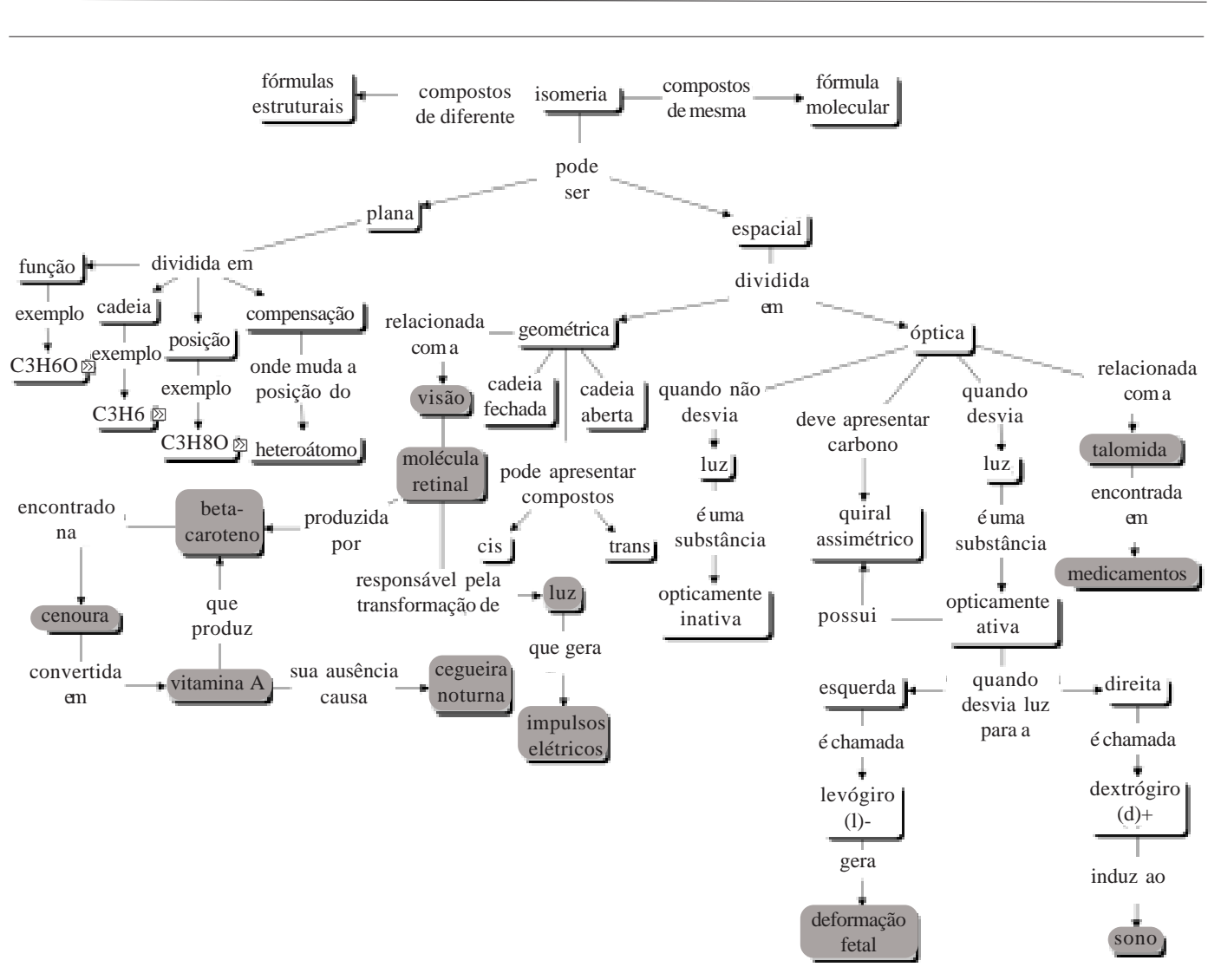

Figura 3. MC sobre isomeria produzido pelos alunos, como tarefa do encontro 5, após a discussão sobre as repercussões da isomeria em organismos vivos. Os conceitos destacados em cinza estão relacionados à biologia, evidenciando o estabelecimento de relações interdisciplinares. 
É interessante notar que esses conceitos químicos funcionaram como "subçunsores" para a ancoragem dos conceitos biológicos. O resultado desse processo é a diferenciação progressiva de conceitos químicos, por meio de conceitos biológicos: além das relações interdisciplinares, verifica-se que o conhecimento químico agora é contextualizado com base em conceitos de outra área do conhecimento. Isso amplia as possibilidades de interação dessa rede cognitiva sobre isomeria com outros conhecimentos dos alunos. Uma conseqüência desse processo é a aproximação da química escolar daqueles assuntos cotidianos que exigem conhecimentos químicos como elementos fundamentais para sua decodificação e interpretação.

A diferenciação progressiva dos conceitos relacionados com a isomeria plana, geométrica e óptica pode ser comparada nos MCs produzidos pelos alunos (Figura 2 e 3). Mesmo não sendo privilegiados nas discussões, os conceitos relacionados com isomeria plana (função, cadeia, posição e compensação) foram aprimorados, e alguns exemplos foram adicionados utilizando-se um recurso do programa CmapTools: os conceitos " $\mathrm{C}_{3} \mathrm{H}_{6} \mathrm{O}$ ", " $\mathrm{C}_{3} \mathrm{H}_{6}$ " e " $\mathrm{C}_{3} \mathrm{H}_{8} \mathrm{O}$ " são expansíveis, e apresentam "propanona e propanal", "propeno e cilopropano", e "metóxietano" como exemplos para isomeria plana de função, cadeia e posição, respectivamente. Apesar desse avanço, cabe ressaltar que a fórmula $\mathrm{C}_{3} \mathrm{H}_{8} \mathrm{O}$ não produz um par de isômeros planos de posição. Por outro lado, fica evidente o papel do MC em explicitar esse tipo de falha conceitual para o professor, que pode alertar os alunos quanto à adequação do conceito (exemplo) mencionado.

Os conceitos mais alterados foram aqueles relacionados com isomeria espacial. A diferenciação progressiva dos conceitos "geométrica" e "óptica" ilustra claramente os avanços obtidos pelos alunos. Antes das discussões envolvendo o 11-cis-retinal e a talidomida, somente os conceitos "cis" e "trans" estavam relacionados com o conceito "geométrica", e o conceito "óptica" relacionava-se somente com o conceito "moléculas assimétricas" (Figura 2). Após as atividades, os conceitos "geométrica" e "óptica" foram diferenciados por meio de conceitos biológicos: os conceitos extraídos sobre o papel do 11-cis-retinal foram relacionados com a isomeria geométrica, enquanto os conceitos extraídos sobre a talidomida foram relacionados com a isomeria óptica (Figura 3). As fronteiras disciplinares podem ser delineadas separando-se os conceitos em branco (químicos) daqueles com fundo cinza (biológicos).

A pertinência e a adequação das relações estabelecidas pelos estudantes podem ser discutidas pelo professor, no sentido de favorecer o exercício do pensamento crítico e a utilização de estratégias metacognitivas que levem o aluno a pensar sobre o que está aprendendo. Por outro lado, uma reflexão com base nas relações estabelecidas pelos estudantes deve servir ao docente para analisar a própria prática e favorecer ações e práticas que intensifiquem a utilização de temas interdisciplinares na sala de aula.

\section{Considerações finais}

Os MCs são instrumentos importantes para se avaliar o resultado de atividades didáticas interdisciplinares, bem como para se monitorar o avanço dos alunos no processo de integração de conhecimentos de campos disciplinares distintos. Deve-se destacar a importância dos MCs na avaliação da aprendizagem e na percepção de "fronteiras disciplinares", tão difíceis de serem analisadas no dia-a-dia escolar. A repercussão biológica da isomeria de compostos orgânicos serviu para criar vínculos interdisciplinares entre a Química e a Biologia, 
Mapeamento conceitual como estratégia...

permitindo levar a bioquímica para o contexto do Ensino Médio. O interesse crescente por essa área da ciência, devido a temas relacionados com transgenia, células-tronco e terapia gênica, aumentou a motivação dos alunos e permitiu contextualizar um tópico de química considerado tradicionalmente árido pelos estudantes.

É necessário ressaltar que os MCs não buscam evidenciar as "partes” de um conceito, uma vez que os conceitos possuem significados, e não "partes" (MOREIRA, 2000). Trata-se de identificar os conceitos-chave de certo corpo de conhecimentos, organizá-los em um diagrama e relacioná-los explicitamente com outros conhecimentos. Nesse contexto, os MCs apresentam-se como um instrumento de negociação de significados, que pode ser utilizado na sala de aula para ensinar e aprender de forma interdisciplinar, transpondo as barreiras disciplinares usualmente encontradas nas escolas.

Apesar dos benefícios que podem ser obtidos por meio dos MCs, sua utilização em sala de aula é muito restrita. Os motivos responsáveis por esse fato podem ser: o desconhecimento dessa estratégia, a dificuldade em compreender seu papel no processo de ensino e aprendizagem, e a falta de informações em como interpretá-los e explorá-los para o planejamento de ações didáticas. Por isso, é importante o desenvolvimento de estudos destinados a seu entendimento e à divulgação dessa estratégia junto aos professores, que são os potenciais usuários dos MCs.

\section{Agradecimentos}

Os autores agradecem a Dervile Ariza e Melissa Dazzani, por viabilizarem a utilização dos MCs no colégio que participou dessa investigação, bem como aos alunos que participaram voluntariamente das atividades. John W. A. Donner Jr. agradece ao Conselho Nacional de Desenvolvimento Científico e Tecnológico pela bolsa de iniciação científica (CNPq/PIBIC 111006/2005-8). Paulo R. M. Correia agradece à Fundação de Amparo à Pesquisa do Estado de São Paulo, por financiar a participação na $2^{\text {a }}$ Conferência Internacional sobre Mapeamento Conceitual (FAPESP 2006/03083-0).

\section{Referências}

ARAÚJO E OLIVEIRA, J. B.; CHADWICK, C. Aprender e ensinar. 6. ed. Belo Horizonte: Alfa Educativa, 2004.

ATKINS, P. W. Moléculas. São Paulo: Edusp, 2000.

AUSUBEL, D. P.; NOVAK, J. D.; HANESIAN, H. Educational psychology. New York: Holt, Rinehart and Winston, 1978.

BRASIL. Ministério da Educação e Cultura. Secretaria de Educação Fundamental.

Parâmetros Curriculares Nacionais: terceiro e quarto ciclos do ensino fundamental. Brasília: MEC/SEF, 1998. 
Correia, P. R. M.; Donner Jr., J. W. A.; Infante-Malachias, M. E.

BRASIL. Ministério da Educação. Secretaria de Educação Média e Tecnológica.

Parâmetros Curriculares Nacionais para o Ensino Médio. Brasília: MEC/Semtec, 1999.

CAÑAS, A. J.; NOVAK, J. D. Re-examining the foundations for effective use of concept maps. In: INTERNATIONAL CONFERENCE ON CONCEPT MAPPING, 2., 2006, San Jose. Proceedings... San Jose: Universidad de Costa Rica, 2006. p. 247-55. v. 1.

DE MEIS, L. Ciência, educação e o conflito humano-tecnológico. 2. ed. São Paulo: Senac, 2002.

FELTRE, R. Fundamentos da química. 3. ed. São Paulo: Moderna, 2001.

FREIRE, P. Pedagogia da autonomia: saberes necessários à prática educativa. 34. ed. São Paulo: Paz e Terra, 1996.

HOBSBAWN, E. J. Era dos extremos: o breve século XX (1914-1991). São Paulo: Companhia das Letras, 2001.

HORTON, P. B. et al. An investigation of the effectiveness of concept mapping as an instructional tool. Science Education, v. 77, p. 95-111, 1993.

KLEIN, J. T. Crossing boundaries: knowledge, disciplinarities and interdisciplinarities. Charlottesville: University Press of Virginia, 1996.

KRASILCHIK, M. Interdisciplinaridade: problemas e perspectivas. Revista da USP, São Paulo, n. 39, p. 38-43, 1998.

MENEZES, L. C. Ensinar ciências no próximo século. In: HAMBURGER, E. W.; MATOS, C. (Orgs.). O desafio de ensinar ciências no século XXI. São Paulo: Edusp, 2000. p. 48-54.

MORAN, J. Interdisciplinarity: the new critical idiom. Londres: Routledge, 2002.

MOREIRA, M. A. Aprendizaje significativo: teoria y práctica. Madrid: Visor, 2000.

.; BUCHWEITZ, B. Novas estratégias de ensino e aprendizagem: os mapas conceituais e o Vê epistemológico. Lisboa: Plátano Edições Técnicas, 1993.

.; MASINI, E. F. S. Aprendizagem significativa: a teoria de David Ausubel. São Paulo: Moraes, 1982.

MORIN, E. Os sete saberes necessários à educação do futuro. 5. ed. São Paulo: Cortez, 2002.

NOVAK, J. D. Learning, creating, and using knowledge: concept maps as facilitative tools in schools and corporations. New Jersey: Lawrence Erlbaum Associates, 1998.

Concept mapping: a useful tool for science education. Journal of Research in Science Teaching, v. 27, p. 937-49, 1990.

NOVAK, J. D.; GOWIN, D. B. Learning how to learn. New York: Cambridge University Press, 1984. 
Mapeamento conceitual como estratégia...

ROTH, W. M. Student views of collaborative concept mapping: an emancipatory research project. Science Education, v. 78, p. 1-34, 1994.

; ROYCHOUDHURY, A. Science discourse through collaborative concept mapping: new perspectives for the teacher. International Journal of Science Education, v. 16, p. 437-55, 1994.

TSAI, C. C. Enhancing science instruction: the use of 'conflict maps'. International Journal of Science Education, v. 22, p. 285-302, 2000.

UNESCO. Unesco world report: towards knowledge societies. Paris: Unesco Publishing, 2005.

WANDERSEE, J. H. Concept mapping and the cartography of cognition. Journal of Research in Science Teaching, v. 27, p. 923-36, 1990. 